\title{
Surveys of Neonatal Bilirubin An Evaluation
}

\author{
By B. G. Blijenberg, H. J. Brouwer, H. A. Roetering and B. Leijnse
}

Academic Hospital Rotterdam-Dijkzigt, Department of Clinical Chemistry, Rotterdam, The Netherlands

(Received November 18, 1983/June 16, 1984)

Summary: Experience in surveying the neonatal bilirubin determination in the Netherlands is described. Initially it was organized as a local activity (the Rotterdam area), then later enlarged to a national scale (some 150 participants).

A number of items is discussed i.e. the initial improvements, which stàbilized at an interlaboratory imprecision of about $8 \%$, and further changes that could improve this rather high imprecision.

\section{Auswertung von Ringversuchen für die Bilirubinbestimmung bei Neugeborenen}

Zusammenfassung: Die mit Ringversuchen zur Bestimmung von Bilirubin bei Neugeborenen in den Niederlanden gemachten Erfahrungen wurden ausgewertet. Die Ringversuche wurden anfangs im Gebiet von Rotterdam organisiert, später auf nationale Ebene ausgedehnt (150 Teilnehmer).

Es wird u.a. die anfängliche Verbesserung der Präzision von Tag zu Tag auf $8 \%$ erörtert und diskutiert, wie diese eher hohe Impräzision weiter verringert werden kann.

\section{Introduction}

In a previous article we described the results of three surveys on the analysis of neonatal bilirubin in the Rotterdam area (15 laboratories). It became clear that under strict guidance of the organizing laboratory a considerable improviement with respect to the interlaboratory precision could be obtained (1).

We also discussed several aspects of methodology and standardization. During the same period comparäable work done in Australia was published $(2,3)$. Although several differences exist in the work of both groups the overall result was the same, i.e. an existing unacceptable interlaboratory imprecision which could be influenced positively by the organizing laboratory. Since our publication, we have continued our efforts in this field by organizing new surveys with an increasing number of participating laboratories (namely 21,31 and 34 respectively). This work recently culminated in a survey under the auspices of our National Quality Assessment Founda- tion with some 150 laboratories (4). In addition we have reported and discussed our results at congresses $(5,6)$, local meetings on quality control and in many personal contacts. Therefore it seemed appropriate to review our experience in this field.

\section{Materials and Methods}

The surveys 4,5 , and 6 were organized in such a way that they were comparable with the previous surveys. Thus, the materials, bilirubin, albumin, specimens and commercial preparations were the same and handled in the same way as described in l.c. (1). Every participant received one box with specimens containing sera for a precision study (pooled baby sera and commercial samples) and sera for the determination of the accuracy (standards, the same commercial samples and haemoglobin-containing samples). The surveys were held in November 1980, November 1981 and November 1982.

Survey 7 , the national survey, held in June 1983, was organized in a different way.

With the help of Vink et al. (8) and of the Dutch Institute of Public Health, four samples were prepared, two based on human albumin (samples A and B, tables 3 and 4 ) and two based on human serum (samples $C$ and $D$, tables 3 and 4 ). 
The entire process regarding the preparation of these samples will be described by this workgroup in a separate paper by Vink et al. (8). We only want to mention now that the samples were sent throughout the country lyophilized in tightly stoppered brown bottles packaged in boxes. In addition, these samples were sent to six "reference" laboratories by Vink where analyses were performed according to a rigid protocol (8). Only the values from Hertz's method are used in table 4.

As a check on the linearity of the spectrophotometric measurements two samples of cobaltous sulphate solutions were prepared, 10.0 and $23.0 \mathrm{~g} / \mathrm{l}$ each, in a way comparable with the method of Doumas et al. (14).

\section{Results}

In table 1 the interlaboratory precision of the surveys 4,5 and 6 is given. For comparison, part of the previously published relevant data from survey 3 , is also provided.

It is worthwhile to divide the methods used by the participating laboratories into three categories (see also l.c. (1)): a. modifications of the Jendrassik-Grof determination

b. direct reading methods with buffer dilution, in most cases the method used in the Du Pont Automatic Clinical Analyser and the method published by Hertz et al. (7)

c. direct reading methods without dilution, in most cases the method used in the OHC Photo Ictometer.

In table 2, surveys 4,5 and 6 are subdivided with respect to the interlaboratory imprecision of the above described methods $a, b$ and $c$.

For the sake of simplicity only the data from the pooled neonatal sera are given.

The combined information of surveys $1-6$ led to the organization of survey 7 . This survey for which the Dutch National Quality Assessment Foundation took care of the distribution of the samples, was held in June 1983. The most striking differences from the foregoing surveys were the following:

Tab. 1. Results of surveys $3,4,5$ and 6 .

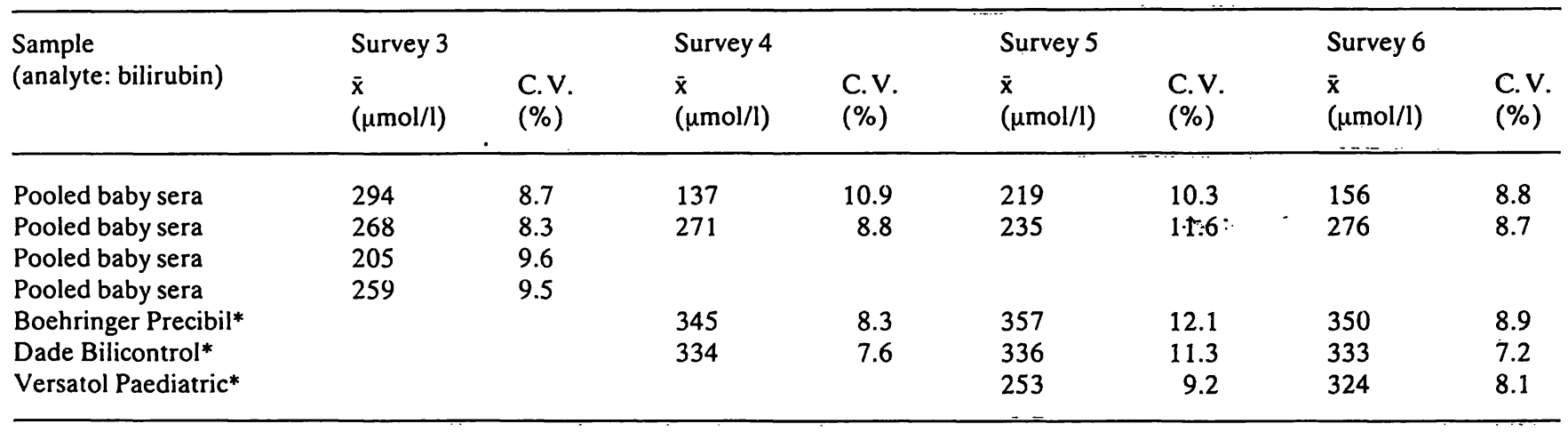

Survey 3: 15 participants, held April 1979

Survey 4: 21 participants, held November 1980

Survey 5: 31 participants, held November 1981

* The commercial sera did not always have the same lot number over the various surveys.

Tab. 2. Subdivision of surveys 4,5 and 6 .

\begin{tabular}{|c|c|c|c|c|c|c|c|c|c|}
\hline \multirow[b]{2}{*}{$\begin{array}{l}\text { Analyte: } \\
\text { bilirubin }\end{array}$} & \multicolumn{3}{|c|}{ Diazo technique } & \multicolumn{3}{|c|}{ Direct reading with dilution } & \multicolumn{3}{|c|}{ Direct reading without dilution } \\
\hline & $\begin{array}{l}\bar{x} \\
(\mu \mathrm{mol} / \mathrm{l})\end{array}$ & $\begin{array}{l}\text { C.V. } \\
(\%)\end{array}$ & $\mathrm{n}$ & $\begin{array}{l}\bar{x} \\
(\mu \mathrm{mol} / \mathrm{l})\end{array}$ & $\begin{array}{l}\text { C.V. } \\
(\%)\end{array}$ & $\mathrm{n}$ & $\begin{array}{l}\bar{x} \\
(\mu \mathrm{mol} / \mathrm{l})\end{array}$ & $\begin{array}{l}\text { C.V. } \\
\%\end{array}$ & $\mathrm{n}$ \\
\hline Survey 4 & $\begin{array}{l}126 \\
264\end{array}$ & $\begin{array}{r}11.9 \\
6.1\end{array}$ & $\begin{array}{l}6 \\
6\end{array}$ & $\begin{array}{l}141 \\
279\end{array}$ & $\begin{array}{l}7.8 \\
5.5\end{array}$ & $\begin{array}{l}8 \\
8\end{array}$ & $\begin{array}{l}142 \\
267\end{array}$ & $\begin{array}{l}9.8 \\
8.3\end{array}$ & $\begin{array}{l}7 \\
7\end{array}$ \\
\hline Survey 5 & $\begin{array}{l}205 \\
217\end{array}$ & $\begin{array}{l}5.6 \\
4.8\end{array}$ & $\begin{array}{l}6 \\
6\end{array}$ & $\begin{array}{l}218 \\
234\end{array}$ & $\begin{array}{l}5.6 \\
5.5\end{array}$ & $\begin{array}{l}13 \\
13\end{array}$ & $\begin{array}{l}227 \\
245\end{array}$ & $\begin{array}{l}13.9 \\
15.8\end{array}$ & $\begin{array}{l}12 \\
12\end{array}$ \\
\hline Survey 6 & $\begin{array}{l}143 \\
257\end{array}$ & $\begin{array}{r}8.6 \\
10.3\end{array}$ & $\begin{array}{l}7 \\
7\end{array}$ & $\begin{array}{l}154 \\
273\end{array}$ & $\begin{array}{l}5.6 \\
4.7\end{array}$ & $\begin{array}{l}14 \\
14\end{array}$ & $\begin{array}{l}165 \\
290\end{array}$ & $\begin{array}{l}8.3 \\
9: 0\end{array}$ & $\begin{array}{l}12 \\
12\end{array}$ \\
\hline
\end{tabular}


a. the number of participants was much higher i.e. about 150

b. the samples were meticulously prepared in the Dutch Institute of Public Health (8)

c. the method of Hertz et al. (7) was chosen as a reference procedure as before (1).

In table 3 the results of all participants are given.

Tab. 3. Results of survey 7 .

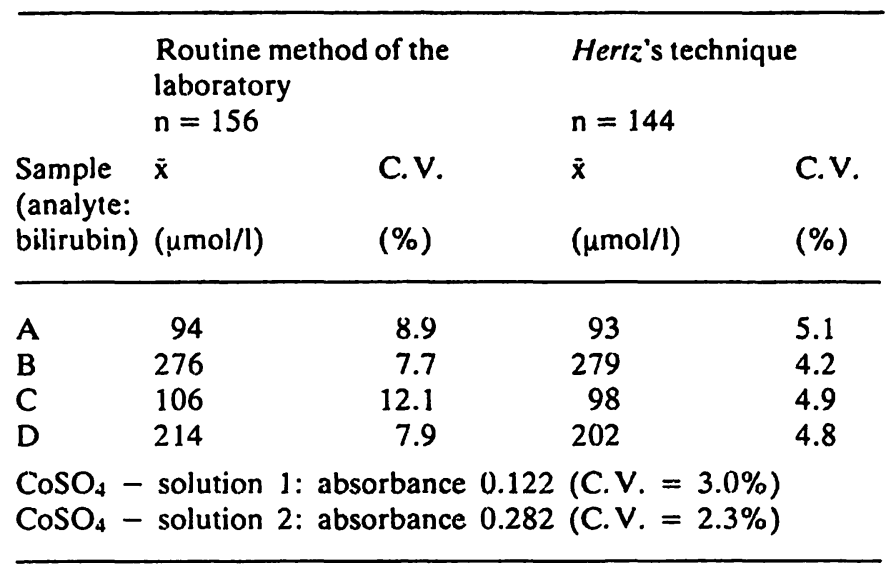

\section{Discussion}

As may be clear, we have put much effort into the neonatal bilirubin field both on the analytical chemical side $(9,10)$ and the organization side $((1)$, this paper). Thus, the question arises as to whether we are satisfied with the results. Without doubt, considerable progress has been made. This is best illustrated by comparing the results of the Rotterdam area. Although the results of the surveys 4, 5, 6 and 7 of this area are not separately given they were more or less comparable with the results of survey 3 , i.e. an interlaboratory imprecision of $6-10 \%$ (without cor= rection based on standards) which is much better than the results of survey 1 (average coefficient of variation about $15 \%$ ). However, we have made no progress in the Rotterdam area since survey 3 (April $1979)$, although the "tools" were provided $(1,2,3)$. The same holds true with the other participants in later surveys. This was disappointing, because we feel that the coefficients of variation found are too high for this important determination in paediatrics.

Part of the imprecision may be explained qualitatively. If we look at the questionnaires and the results of the surveys 6 and 7, then a number of conclusions can be drawn, not only with respect to the interlaboratory precision but also to the accuracy.
1. Sometimes a relative low within-run precision is seen.

2. The influence of haemoglobin, a well known interfering factor $(9,11)$, is sometimes unacceptable high (no data mentioned).

3. The way intralaboratory quality control is performed is sometimes very poor; for instance only a check with a bilirubin containing sample of about $40 \mu \mathrm{mol} / 1$ whereas most of the patient samples are about $200 \mu \mathrm{mol} / \mathrm{l}$ or higher.

4. The calibration is very diverse i.e. commercial sera (Boehringer Precibil, Dade Bilicontrol, Versatol Paediatric and others), patient sera (adult), own standards, calibration factor, methyl orange solution and Hertz's method.

5. Instrumental or method failures resulting in a non linear calibration graph.

Of course, not all participants are equally experienced in the neonatal field, on account of their sometimes very modest workload. Nevertheless, many of them do neonatal bilirubin determinations in their laboratory. There are similarities with the situation we met in the Netherlands several years ago with respect to the determination of haemoglobin (12). With the help of a reference method, a stable haemoglobin cyanide standard and commercially available haemoglobin solutions, an interlaboratory trial resulted in a coefficient of variation of about $3 \%$. According to Van Assendelft (12) it should be possible nevertheless to lower this figure because it consists mainly of diluting and photometric errors. Having all this in mind we organized the seventh survey. We wished to study and possibly improve the national "state of the art" with respect to accuracy and precision. Besides, we wished to compare the routine method of the participating laboratories with Hertz's method. We consider this last method as a very suitable "reference" method for determining neonatal bilirubin not only for its simplicity of operation and ease of control but also for its excellent correlation with the method of Jendrassik \& Grof (7).

From table 3 it is clear that the national precision data are comparable with the data scored before (tab. 1) with respect to the routine methods. As a matter of fact, we expected these results, despite all efforts for improvement and accompanying frustrations. We still feel that considerable improvements can be made by means of rigid standardization. This opinion is based on earlier experience $(1,3)$ as well as the study of the questionnaires.

We are reasonably satisfied with the data obtained with Hertz's technique. Many of the participants performed this technique for the first time. The only pit- 
falls in the method, the dilution step and the spectrophotometric measurement, can be controlled very easily. With respect to the last item, the measurement of the cobaltous sulphate solutions, we gave some information concerning this step. The average "national" linearity was good. The division of the value for the average absorbance for solution II by the same value for solution I gives a factor of 2.30 , which is the same for the division of the weight values (see Materials and Methods). Concerning the accuracy of the absorbance measurements, it is difficult to give a judgement when working with cobaltous sulphate solutions. However, our data were comparable with the data mentioned by Doumas et al. (14). The precision, although it can be improved, was about the same as obtained earlier (13). This leads us to the last item of survey 7 i.e. the accuracy of the routine methods. A very serious attempt has been made to tackle this problem. In a separate publication all details concerning the production and the organisation of the samples and the protocol will be given by Vink et al. (8). They have investigated the possibility of producing stable and reliable standard preparations of bilirubin. For the present, it is enough to mention the analytical data, as displayed in table 4. The methodological subdivision is also given in this table.
Comparing, in table 4 , the data obtained with the "reference" laboratories (see Materials and Methods), a lack of accuracy is apparent in the direct reading methods without dilution. The other methods, the diazo technique as well as the direct reading methods with dilution, correlate' better, despite the moderate precision.

In conclusion we may say that there is a need for many participants to study the operation of their neonatal bilirubin determinations. Furthermore, it seems helpful to produce high quality bilirubin standards and to use them on a national scale.

\section{Acknowledgement}

The authors wish to thank all participants of the various surveys. Furthermore thanks are due to:

1. Dr. C. L. J. Vink (St. Joseph Hospital, Eindhoven) for his help with the preparation of the samples for survey 7 as well as his participation in the discussion.

2. Dr. J. C. Koedam (Dutch Institute of Public Health, Bilthoven) for materials and the manufacturing of these materials for survey 7.

3. Professor Dr. A. Jansen (Dutch Quality Assessment Foundation, Nijmegen) for his help in organizing survey 7 as well as his stimulating comments.

4. Dr. G. J. M. Boerma for reading the manuscript.

Tab. 4. Subdivision of survey 7 .

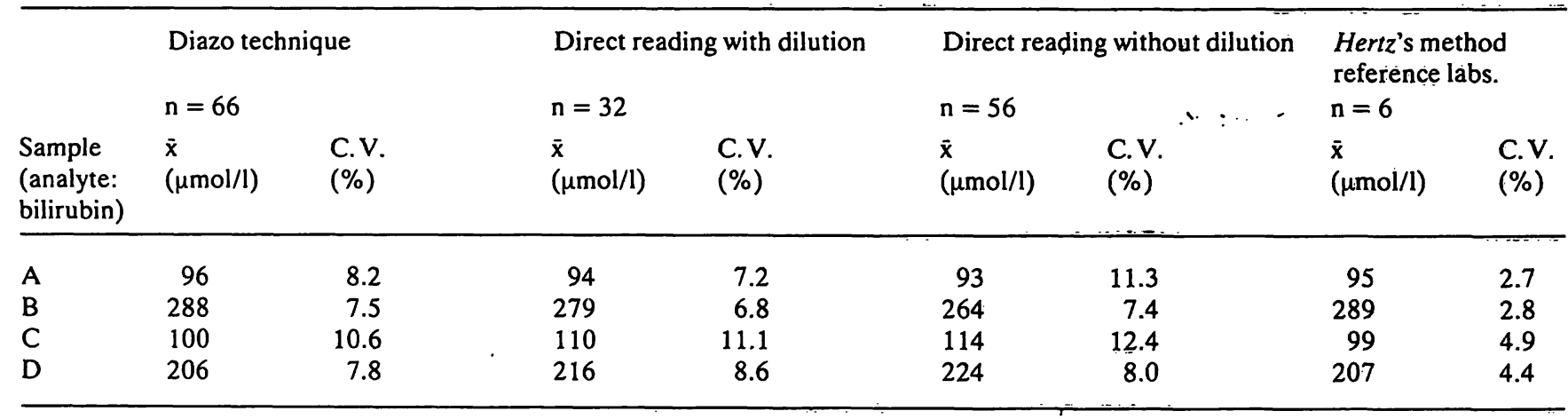

\section{References}

1. Blijenberg, B. G. \& Leijnse, B. (1980) J. Clin. Chem. Clin. Biochem. 18, 27-30.

2. St. John, A. \& Penberthy, L. A. (1979) J. Clin. Pathol. 32, 794-797.

3. Watkinson, L. R., St. John, A. \& Penberthy, L. A. (1982) J. Clin. Pathol. 35, 52-58.

4. Jansen, A. P., Van Kampen, E. J., Leijnse, B., Meijers, C. A M. \& Van Munster, P. J. J. (1977) Clin. Chim. Acta 74, 191201.

5. Blijenberg, B. G. (1979) Ann. Clin. Biochem. 16, Suppl., 33.

6. Blijenberg, B. G. \& Leijnse, B. (1981) J. Clin. Chem. Clin. Biochem. 19, 215.

7. Hertz, H., Dybkaer, R. \& Lauritzen, M. (1974) Scand. J. Clin. Lab. Invest. 33, 215-230.

8. Vink, C. L. J. et al. to be published.
9. Blijenberg, B. G., Brouwer, H. J. \& Leijnse, B. (1978) J. Clin. Chem. Clin. Biochem. 16, 425-428.

10. Blijenberg, B. G. \& Leijnse, B. (1979) J. Clin. Chem. Clin. Biochem. 17, 303-308.

11. Michaëlsson, M. \& Sjölin,. B. (1965) Acta Paediatr. Scand. $54,325-330$.

12. Van Assendelft, O. W. (1976) Clin. Chim. Actā 70, 161169.

13. Jansen, A. P. personal communication.

14. Doumas, B. T., Bayse, D. D., Carter, R. J., Peters, T. \& Schaffer, R. (1981) Clin. Chem. 27, 1642-1650.

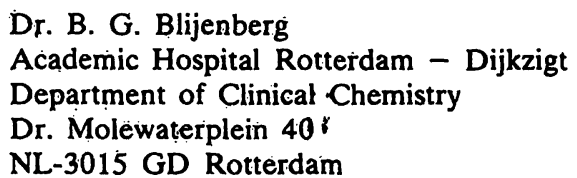

